\title{
Intratumor heterogeneity index of breast carcinomas based on DNA methylation profiles
}

Emanuel M. Campoy ${ }^{1,2^{*}}$, María T. Branham¹, Luis S. Mayorga ${ }^{1,2}$ and María Roqué 1,3

\begin{abstract}
Background: Cancer cells evolve and constitute heterogeneous populations that fluctuate in space and time and are subjected to selection generating intratumor heterogeneity. This phenomenon is determined by the acquisition of genetic/epigenetic alterations and their selection over time which has clinical implications on drug resistance.

Methods: DNA extracted from different tumor cell populations (breast carcinomas, cancer cell lines and cellular clones) were analyzed by MS-MLPA. Methylation profiles were used to generate a heterogeneity index to quantify the magnitude of epigenetic heterogeneity in these populations. Cellular clones were obtained from single cells derived of MDA-MB 231 cancer cell lines applying serial limiting dilution method and morphology was analyzed by optical microscopy and flow cytometry. Clones characteristics were examined through cellular proliferation, migration capacity and apoptosis. Heterogeneity index was also calculated from beta values derived from methylation profiles of TCGA tumors.

Results: The study of methylation profiles of 23 fresh breast carcinomas revealed heterogeneous allele populations in these tumor pieces. With the purpose to measure the magnitude of epigenetic heterogeneity, we developed an heterogeneity index based on methylation information and observed that all tumors present their own heterogeneity level. Applying the index calculation in pure cancer cell populations such as cancer cell lines (MDA-MB 231, MCF-7, T47D, HeLa and K-562), we also observed epigenetic heterogeneity. In addition, we detected that clones obtained from the MDA-MB 231 cancer cell line generated their own new heterogeneity over time. Using TCGA tumors, we determined that the heterogeneity index correlated with prognostic and predictive factors like tumor size $(p=0.0088)$, number of affected axillary nodes $(p=0.007)$, estrogen receptor expression $(p<0.0001)$ and HER2 positivity $(p=0.0007)$. When we analyzed molecular subtypes we found that they presented different heterogeneity levels. Interestingly, we also observed that all mentioned tumor cell populations shared a similar Heterogeneity index (HI) mean.
\end{abstract}

Conclusions: Our results show that each tumor presents a unique epigenetic heterogeneity level, which is associated with prognostic and predictive factors. We also observe that breast tumor subtypes differ in terms of epigenetic heterogeneity, which could serve as a new contribution to understand the different prognosis of these groups.

Keywords: Intratumor heterogeneity - promoter methylation, TCGA - heterogeneity index - breast Cancer - cellular clones, Prognosis and predictive factors

\footnotetext{
* Correspondence: ecampoy@mendoza-conicet.gob.ar

${ }^{1}$ HHEM-CONICET, Av del libertador, 80 Mendoza, Argentina

${ }^{2}$ Facultad de Ciencias Médicas, Av del Libertador 80, Universidad Nacional de

Cuyo, Mendoza, Argentina

Full list of author information is available at the end of the article
}

(c) The Author(s). 2019 Open Access This article is distributed under the terms of the Creative Commons Attribution 4.0 International License (http://creativecommons.org/licenses/by/4.0/), which permits unrestricted use, distribution, and reproduction in any medium, provided you give appropriate credit to the original author(s) and the source, provide a link to the Creative Commons license, and indicate if changes were made. The Creative Commons Public Domain Dedication waiver (http://creativecommons.org/publicdomain/zero/1.0/) applies to the data made available in this article, unless otherwise stated. 


\section{Background}

It has been estimated that 14.1 million new cancer cases and 8.2 million cancer deaths occurred in 2012 worldwide [1]. Breast cancer ranks as the most frequent cancer in women in less developed regions, contributing with 25\% of the new cases diagnosed in 2012 [1]. Normally, breast cancers of advanced stages have poorer prognosis [2].

Cancer is a disease defined by alterations at the genomic, epigenomic, transcriptomic and proteomic level. The interplay between these events triggers the acquisition of cancer hallmarks which, by occurring in different cells, evolve and can constitute a heterogeneous tumor cell population. The populations fluctuate in space and time and are subjected to selection [3]. It is reasonable therefore to sustain that intratumor heterogeneity (ITH) is determined by two events: first, by the acquisition of genetic/epigenetic alterations; and secondly, through their selection over time [4]. Although the ITH is frequently related to the spatial organization of cells in a tumor, it is also necessary to consider the temporal dimension for the evolution of cancer cell populations. One of the models that synthetizes spatial and temporal heterogeneity of tumors is "the clonal evolution model of cancer" proposed by Peter Nowell in 1976 [5]. This model proposed that endogenous and exogenous factors induce mutational processes providing the fuel for genetic variation between cancer cells, which determine selection of cancer cell populations [3]. This evolutionary model was useful to understand tumor growth and treatment failure and also contributed to reveal the increased tumor aggressiveness that occurs during the natural history of advanced solid tumors [6].

Most of the current therapies treat cancer as a homogenous disease, which has clinical implications on drug resistance. It has been described that anti-neoplasic drugs act specifically on cellular clones with, for example, mutated oncogenes, leaving other populations lacking these mutations unaltered. In this way the untargeted clones, can proliferate and maintain tumor progression after the drug treatment [7] [8]. It has also been determined that continued drug exposure produces selection of the surviving cells, which increases the evolution rate and allows induction of more aggressive clones with new properties [9]. So far there is enough evidence to consider the study of ITH a key feature to enhance treatment strategies.

During cancer progression, aberrant promoter methylation of tumor suppressor genes (TSG) is one of the most common alterations in solid tumors [10] and has been described as an early event in many tumor types, including breast tumors [11] [12] [13]. The CpG sites located in these TSG are normally unmethylated in healthy cells, but frequently methylated in cancer cells. In fact, several tumor types (or tumor subtypes) present an specific methylation profile [14] [15]. Methylation has a direct impact on different pathways of cancer hallmarks, including
DNA repair, cell cycle regulation and evading apoptosis [16] [17]. Although epigenetic modifications are dynamic, some marks remain through cancer progression [18] [19]. Considering this, the epigenetic information configurates the epigenomic landscape of each tumor.

Distinct methods have been developed to study genetic ITH: deep-sequencing, multi-region sequencing and single cell DNA sequencing [20] [21] [22] [23]. Several studies also consider the genomic information to infer ITH which is afterward associated with prognostic or predictive factors [24]. For example, breast cancer patients with low genomic ITH were more likely to have complete pathological response to neoadjuvant chemotherapy [25]. In this work we propose to quantify ITH using a mathematical approach to calculate a heterogeneity index (HI) from methylation profiles of breast tumors, cancer cells lines and public datasets.

\section{Methods}

\section{Patients and tumor samples}

Twenty three patients treated in the Gineco-Mamario Institute of Mendoza with breast cancer were enrolled after obtaining their informed consent based on the scientific and ethical principles of the World Medical Association's Declaration of Helsinki. Ethical approval was obtained from the Ethics Committee of the Faculty of Medical Sciences, from the National University of Cuyo, Mendoza, Argentina. All tumors presented clinical-pathological data, i.e. tumor type, tumor stage $(T, N, M)$, side, tumor grade, mitotic index, patient age, ER expression, PR expression, HER2 expression). A database containing the clinical-pathological information and DNA methylation profiles was generated.

\section{Materials}

Dulbecco's Modified Eagle Medium (D-MEM), RPMI Medium and Penicillin-Streptomycin were obtained from Gibco Laboratories (Thermo Fisher Scientific, Argentina) and fetal bovine serum was obtained from Internegocios S.A. Mercedes, Buenos Aires. DNA extraction kits (PureLink ${ }^{\oplus}$ Genomic DNA, Thermo Fisher Scientific). MS-MLPA kits manufactured by MRC-Holland.

\section{Cell culture}

MDA-MB 231, MCF7, T47D and HeLa human cells lines were grown in D-MEM while K562 cell line was grown in RPMI. All cell lines were supplemented with $10 \%$ fetal bovine serum, penicillin/streptomicin at $37{ }^{\circ} \mathrm{C}$ in an atmosphere of $95 \%$ air and 5\% CO2, in T-25 flasks and 12,24 and 96 plates to $80 \%$ confluence.

\section{Cell cloning by serial dilution}

MDA-MB 231 cells were used, the initial population was trypsinized and counted using a Neubauer chamber to prepare a cell suspension of 1000 cells $/ \mathrm{ml}$. Serial dilutions 
were generated to obtain 1 cell in $200 \mu$ l of complete D-MEM media and this volume was added per well in a 96 plate in order to obtain a unique cell for each well. Individual cells grew up to $80 \%$ of confluence.

\section{DNA extraction}

Fresh tissues from breast invasive ductal carcinomas (IDC) and surgical margins were frozen at $-80^{\circ} \mathrm{C}$ and fragmented with a frozen mortar. The homogenate was collected and suspended in PBS buffer. All samples were stored for at least $24 \mathrm{~h}$ at $-20^{\circ} \mathrm{C}$ and DNA was collected as previously described (tumor pieces and surgical margins) [26]. Cancer Cell lines and cellular clones were trypsinized and centrifuged (except K-562 that grow in suspension). After homogenization and centrifugation (cellular pellets), DNA extraction was carried out with specific kit (PureLink ${ }^{\ominus}$ Genomic DNA, Thermo Fisher Scientific).

\section{Methylation assays by methyl specific- multiplex ligation probe amplification (MS-MLPA)}

The methylation status of $98 \mathrm{CpG}$ sites located in 54 genes related to cancer was tested in DNA obtained from: IDCs, surgical margins, cancer cell lines (MDA-MB 231, MCF-7, T47D, K-562 and HeLa) and clones derived from MDA-MB 231 by MS-MLPA. Commercial kits ME001, ME002, ME003 and ME011 were used (MRC Holland, Amsterdam, The Netherlands). Reactions were carried out following manufacturer's instructions, including subtle modifications to avoid background signals [15]. Fluorescent PCR products were separated by capillary electrophoresis in a Beckman CEQ8000 sequencer (Beckman Coulter Inc. Fullerton, CA, USA) and analyzed with GeneMarker v1.75 software (Softgenetics LLC, PA, USA).

\section{Heterogeneity index calculation}

To calculate the HI for the methylation observed in five CpG sites, we combined theoretical populations having pure methylated [1] and non-methylated (0) values in different proportions to reproduce the experimental values. The questions were, how many alleles, which alleles, and in what proportions are necessary to explain the epigenetic heterogeneity observed in a cellular population? The criterion to select the most suitable populations and the best proportions of these populations was to minimize the sum of the squared difference between the adjusted and the observed values for the five sites (for an example, see Fig. $1 \mathrm{~B}$ and the corresponding explanation in the Results section). This value was calculated using from 1 to 4 populations. The final HI was the sum of these 4 values. The rationale for this criterion was that the HI was very small when the observed values could be adjusted with just a single population. In contrast, the HI was high when the adjusted and the observed values were very different, and more and more populations were needed to find a combination that reproduced the observed values. To select the best populations and the best proportions of each population to fit the observed value, all the possible populations $\left(2^{\wedge} 5=32\right)$ and all the possible proportions were tested. Proportion is a continuous variable; hence, to make the calculations reasonably fast, the proportion of each population to be tested were limited to $1 / 16$ steps (6.25\%). For example, for a single population it is just $100 \%$ of one of the 32 possible populations that best fitted the data. For two population, all the possible combinations of 2 of the 32 populations were tested in proportions going from 0 to 1 in $1 / 16$ steps (combinations tested: $0-100 \%, 6.25-$ $93.75 \%, 12.5-87.5 \%, \ldots, 87.5-12.5 \%, 93.75-6.25 \%, 100-$ $0 \%)$. The use of a limited set of proportions introduces some limitation to the adjustment to the observed values. The heterogeneity index calculation is available at: https:// heterogeneidad.herokuapp.com/

\section{Migration assays}

MDA-MB 231 clones were cultured in 12 well plates. Cells were incubated overnight in serum-reduced medium containing $0.5 \% \mathrm{FBS}$. Cell surface was then scratched using a sterile $200 \mu \mathrm{L}$ pipet tip and washed with PBS to remove detached cells and debris. Cells were photographed every $12 \mathrm{~h}$ using a TE300 Eclipse microscope equipment (Nikon, Tokyo, Japan). Images were then processed using Image $\mathrm{J}$ software. Reduction of the scratched area was measured and expressed as migration percentage according to the formula: ((Areat0-Areat1)/Areat0) $\times 100$.

\section{Cellular proliferation assay}

MDA-MB 231 clones were plated in 96 well plate and MTT assay was performed. After $24 \mathrm{~h}$ or $48 \mathrm{~h}$ of proliferation, medium containing $1 \mathrm{mg} / \mathrm{mL}$ MTT was added to the cells (MDA-MB231 clones) up to a final concentration of $0.5 \mathrm{mg} / \mathrm{mL}$ and incubated at $37^{\circ} \mathrm{C}$ for $4 \mathrm{~h}$. The medium was then aspired, and the formazan product was solubilized with DMSO. The absorbance at $630 \mathrm{~nm}$ (background absorbance) was subtracted from measures at $570 \mathrm{~nm}$ for each well (3 replicates for each dilution were performed).

\section{Flow cytometry}

MDA-MB231 clones were seeded in 6 well plates, $37{ }^{\circ} \mathrm{C}$ and $5 \% \mathrm{CO}_{2}$. After $24 \mathrm{~h}$ cells were harvested by trypsinization and washed with PBS. After centrifugation, the cells were suspended in $200 \mu$ of PBS and analyzed by flow cytometry (Model BD FACSAria III). Forward and side scatter measurement was registered in order to detect information about the internal cellular complexity (i.e. granularity) and cell size. 


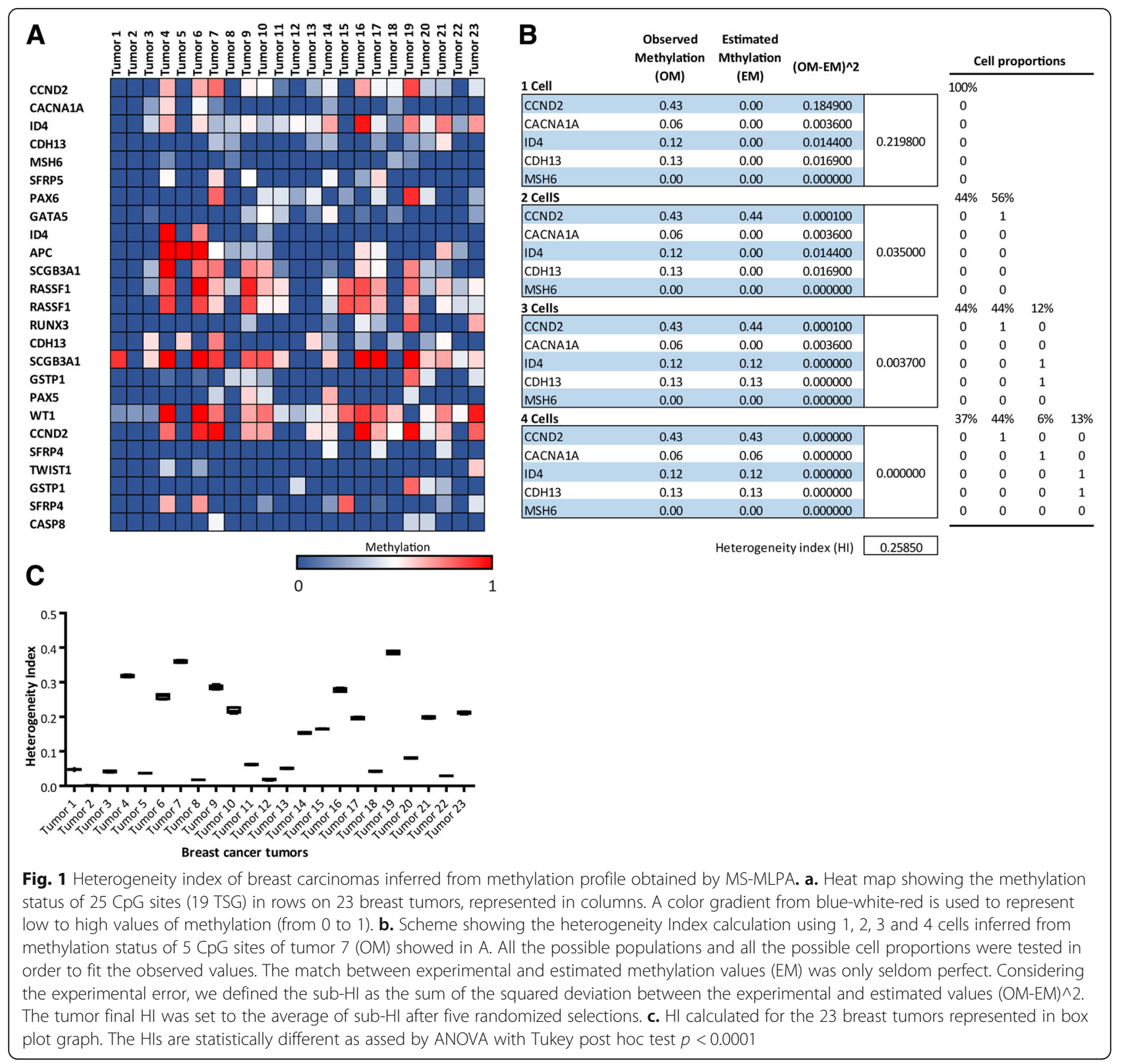

\section{Apoptosis assay}

MDA-MB231 clones were seeded in 6 well plates, $37^{\circ} \mathrm{C}$ and $5 \% \mathrm{CO}_{2}$. After $24 \mathrm{~h}$ cells were exposed to UV radiation for $30 \mathrm{~min}$ and were harvested by trypsinization and washed with PBS. After centrifugation, the cells were suspended in $100 \mu \mathrm{l}$ of binding buffer and then stained with FITC-annexin $\mathrm{V}$ and propidium iodide. After they reacted under dark for $10 \mathrm{~min}$, the cells were resuspended in $100 \mu$ l binding buffer and analyzed by flow cytometry (Model BD FACSAria III).

\section{Database analyses to study the association between $\mathrm{HI}$ and clinical-pathological features}

DNA methylation status of IDCs was retrieved from the public dataset TCGA Breast Cancer (BRCA) using the
UCSC Xena browser (https://xenabrowser.net). HI calculation was performed applying the developed mathematical model considering $15 \mathrm{CpG}$ sites. Association between $\mathrm{HI}$ and clinic-pathologic traits was analyzed in 250 TCGA tumors.

\section{Statistical analysis}

ANOVA analysis was applied to detect significant differences in migration, proliferation, apoptosis and HI calculation assays between distinct tumor, cellular and MDA-MB 231 clone populations. Tukey post-hoc test was applied to find out differences in the mean of population groups. GraphPad Prims v5.3 was used for ANOVA calculation of $\mathrm{HI}$ calculation. For association studies between 
clinical-pathological variables and fresh tumors or TCGA tumors, correlation analyses were performed using the software SPSS v17 (SPSS Inc., Chicago, IL, USA) and the software GraphPad Prims V5.3.

\section{Results}

\section{Methylation heterogeneity for $25 \mathrm{CpG}$ sites in invasive} ductal carcinomas

We established a cohort of 23 fresh tumor fractions derived from patients with invasive ductal breast cancer (Table 1). The tumor piece for analysis was selected by optical microscopy by a specialized anatomopathologist, excluding non-tumoral tissue as much as the technique allowed. After DNA isolation the methylation profile of 98 CpG sites located within 54 cancer related genes was determined by Methyl Specific Multiplex Ligation Probe Amplification assay (MS-MLPA). This is a semi-quantitative method, which calculates for each CpG site the proportion of methylated copies normalized to the total amount of copies of each site in the sample. The 54 analyzed genes are distributed across all the autosomal chromosomes and none are methylated in leukocytes, as assessed in our previous studies [26]. With the purpose

Table 1 Patient and Tumor characteristics

\begin{tabular}{|c|c|c|}
\hline & & Number \\
\hline Total Patients & & 23 \\
\hline Total tumors for methylation analyses & & 23 \\
\hline \multirow[t]{3}{*}{ Age (years)* } & $\leq 40$ & 5 \\
\hline & $>40$ & 14 \\
\hline & Unknown & 4 \\
\hline Tumors with complete anatomo-pathological data & & 22 \\
\hline \multirow[t]{2}{*}{ Axillar Lymph Node Status } & Positive & 9 \\
\hline & Negative & 14 \\
\hline \multirow[t]{3}{*}{ Tumor Grade } & I & 1 \\
\hline & $\|$ & 5 \\
\hline & III & 17 \\
\hline \multirow[t]{7}{*}{ Disease Stage } & 1 & 10 \\
\hline & $2 \mathrm{~A}$ & 4 \\
\hline & $2 \mathrm{~B}$ & 4 \\
\hline & $3 \mathrm{~A}$ & 3 \\
\hline & $3 B$ & 0 \\
\hline & $3 C$ & 1 \\
\hline & Unknown & 1 \\
\hline \multirow[t]{4}{*}{ Molecular Subtypes } & Luminal A & 3 \\
\hline & Luminal B & 16 \\
\hline & HER2 & 2 \\
\hline & $\mathrm{TN}$ & 2 \\
\hline
\end{tabular}

*Mean age: 51.31 years $(\mathrm{SEM}=1.70)$

HER2: Human Epidermal Growth Factor Receptor 2; TN: Triple Negative of define the $\mathrm{HI}$ from the most frequently methylated sites, we chose 25 which were methylated in more than $10 \%$ of the samples.

For these 25 CpG sites (included in Table 2), all the 23 tumors presented a unique methylation signature (Fig. 1A). Interestingly, the proportion of methylated alleles presented intermediate values between 0 and 1 which indicated that the cellular population was not epigenetically homogeneous. The values could result from a mixture of alleles derived from different cell populations from the tumor, and/or from other cells like immune cells, cancer associated fibroblasts, etc. (tumor microenvironment). For example, the methylation for $\mathrm{CpG}$ site CCND2 in Tumor 7 was 0.43 , which means that $43 \%$ of the CCND2 alleles in the tumor fraction were methylated and $57 \%$ were not (see Fig. 1B). Notice that this value cannot be obtained from a pure clonal population, where the only possible values would be 0.5 (for heterozygous genomes), 0 or 1 (for homozygous genomes). So, we can therefore say that a methylation proportion of 0.43 means that CCND2 alleles are heterogeneously methylated in the sample of Tumor 7, which implies that the cellular population is a mixture composed by different tumor cells or tumor cells and stromal cells in which some CCND2 alleles are methylated and others are not. Conversely, the methylation proportion of CCND2 in the sample of Tumor 8 was 0 and this value is compatible with a homogeneous allele population.

Summarizing, methylation proportions different from 0 and 1 (except 0.5 value that may be due to a heterozygous genomes), indicate heterogeneous allele populations in the tumor piece. Hence, the methylation profile of the 25 analyzed $\mathrm{CpG}$ sites had some information about the epigenetic ITH.

\section{Generation of ITH index based on methylation profiles}

With the purpose to measure the magnitude of epigenetic heterogeneity in a sample, we aimed to develop a heterogeneity index (HI) based on the methylation profiles obtained by MS-MLPA. We decided to use $5 \mathrm{CpG}$ sites, a number that proved to be suitable to measure heterogeneity keeping the calculation relatively simple. The basis for the development of the index was to find the smallest number of populations having pure methylated [1] and non-methylated (0) combinations that could explain the observed methylation profile in the sample. For example, if the MS-MLPA of five CpG sites renders the following methylation numbers: $0,0,0,0,0.32$, these values can be explained by the combination of two populations: $68 \%$ of $0,0,0,0,0$ plus $32 \%$ of $0,0,0,0,1$. If, however, the methylation numbers are: $1,0.8,0.4,0.2,0$, two population are not enough, and three populations are required: $20 \%$ of $1,0,0,1,0$ plus $40 \%$ of $1,1,0,0,0$ plus $40 \%$ of $1,1,1,0,0$. When this criterion was used 
Table 260 CpG sites analyzed by MS-MLPA

\begin{tabular}{|c|c|c|c|c|c|}
\hline CpG sites respect to ATG & Gene Name (HGDB) & Chromosome Location & CpG sites respect to ATG & Gene Name (HGDB) & Chromosome Location \\
\hline 72 bp to exon 2 & APC & $5 q 22$ & 346 bp before & MGMT & $10 q 26.3$ \\
\hline 4658 bp before & ATM & $11 q 23$ & 93 bp before & MGMT & $10 q 26.3$ \\
\hline 157 bp after & CACNA1A & 19p13.2 & 151 bp after & MGMT & $10 q 26.3$ \\
\hline 32 bp before & CACNA1G & $17 q 21.33$ & 382 bp before & MGMT & $10 q 26.3$ \\
\hline 8560 bp before & CASP8 & $2 q 33.2$ & 74 bp after ex 1 & MGMT & $10 q 26.3$ \\
\hline 1168 bp before & CCND2 & $12 p 13.3$ & 464 bp after & MGMT & $10 q 26.3$ \\
\hline 1358 bp before & CCND2 & $12 \mathrm{p} 13.3$ & 661 bp before & PAX5 & $9 p 13$ \\
\hline 17 bp before & CD44 & $11 p 12$ & 49 bp before & PAX6 & $11 \mathrm{p} 13$ \\
\hline 411 bp before & CD44 & $11 p 12$ & $43 \mathrm{bp}$ before & PRDM2 & 1 p36.21 \\
\hline 42 bp before & $\mathrm{CDH} 13$ & $16 q 23.3$ & $190 \mathrm{nt}$ after & PYCARD & $16 p 11.2$ \\
\hline $20 \mathrm{bp}$ before & $\mathrm{CDH} 13$ & $16 q 23.3$ & 651 bp before & RARB & $3 p 24.2$ \\
\hline 31 bp after & CDKN2A & $9 p 21.3$ & 824 bp before & RARB & $3 p 24.2$ \\
\hline 407 nt before & CHFR & $12 q 24$ & 888 bp before & RARB & $3 p 24.2$ \\
\hline $400 \mathrm{nt}$ before & CHFR & $12 q 24$ & 141 bp before & RASSF1 & $3 p 21.3$ \\
\hline 714 bp before & DAPK1 & $9 q 22$ & 79 bp before & RASSF1 & $3 p 21.3$ \\
\hline 366,437 bp after & DLC1 & $8 p 22$ & 18 bp before & RUNX3 & 1 p36.11 \\
\hline 366,993 bp after & DLC1 & $8 p 22$ & 232 bp before & SCGB3A1 & $5 q 35$ \\
\hline 163 bp after & ESR1 & $6 q 25.1$ & $17 \mathrm{bp}$ before & SCGB3A1 & $5 q 35$ \\
\hline 112 bp after & ESR1 & $6 q 25.1$ & 42 bp before & SFRP4 & 7p14.1 \\
\hline 658 bp before & GATA5 & $20 q 13.3$ & 82 bp after & SRFP4 & $10 \mathrm{q} 24.1$ \\
\hline 103 bp after & GSTP1 & $11 q 13$ & 275 bp before & SFRP5 & $7 p 14.1$ \\
\hline 245 bp before & GSTP1 & $11 q 13$ & $316 \mathrm{bp}$ before & SFRP5 & $10 q 24.1$ \\
\hline 11 bp before ex 1 & $\mathrm{HICl}$ & $17 p 13$ & 172 bp before & TIMP3 & $22 q 12.3$ \\
\hline 163 bp after & HTLF & $3 q 25.1$ & 300 bp before & TIMP3 & $22 q 12.13$ \\
\hline 953 bp before & ID4 & $6 p 22.3$ & 10,905 bp before & TP53 & $17 p 13.1$ \\
\hline 319 bp before & ID4 & $6 p 22.3$ & 29,790 bp before & TP73 & 1p36.32 \\
\hline 305 bp before & IGSF4 & $11 q 23$ & 29,551 bp before & TP73 & $1 p 36.3$ \\
\hline 72 bp before & IGSF4 & $11 \mathrm{q} 23$ & 220 bp after & TWIST1 & $7 p 21.2$ \\
\hline 464 nt after & KCNQ1 & $11 \mathrm{p} 15.5$ & 80 nt before & VHL & $3 \mathrm{P} 25$ \\
\hline 432 bp before & MGMT & $10 q 26.3$ & 412 bp before & WT1 & $11 \mathrm{p} 13$ \\
\hline
\end{tabular}

with real methylation values obtained by MS-MLPA, we found that the match between experimental and estimated values was only seldom perfect. Taking into consideration the experimental error and some limitation in the estimated values (see, M\&M), we decided to define $\mathrm{HI}$ as the sum of the squared deviation between the experimental and estimated values when using 1 to 4 populations (Fig. 1B). For simplicity's sake, we are considering cell populations having the two allelic CpG sites methylated or not methylated. Hence, the $\mathrm{HI}$ is pooling together intra and inter cellular methylation heterogeneity.

\section{Invasive ductal breast carcinomas present different heterogeneity index}

We aimed to apply the developed HI to compare heterogeneity among tumors basing the analysis on the same
CpG sites. For this, we used five clusters of five randomly selected $\mathrm{CpG}$ sites (25 CpGs). The average of these cluster values was considered as sub-HI. Since the conformation of the five clusters was randomly selected, we wondered if that could influence the index. Hence, we repeated the analysis several times changing the randomized selections. We observed that the dispersion among different sub-HI of a tumor was relatively small (coefficient of variation in the $0-9.72 \%$ range); therefore, the sub-HI average converged when the number of iterations was about 5 . Consequently, the tumor's final HI was set to the average of five sub-HI. When this index was calculated, striking differences were observed among the tumors (ANOVA $p<0.0001$ ). The average and SD HI value of the tumor cohort was $0.15 \pm 0.12$ (Fig. 1C). It is clear that tumors with more methylated sites had 
higher HI. However, notice that there were differences that were not easy to observe, for example the methylation patterns of tumor 4 and 6 looked similar, but their HI were significantly different. The broad range of HI observed in this cohort of IDC analyzed suggests that it can be considered a tumor feature.

\section{Cancer cell lines show methylation heterogeneity}

We were aware that the methylation profile obtained from fresh tumor pieces could contain epigenetic information derived from microenvironment cells. We ignored, however, the precise stromal proportion in the fresh tumor fractions and therefore its potential impact on the methylation estimations. In order to evaluate methylation heterogeneity in pure cancer cell populations, we added an in-vitro model and analyzed the methylation profile of different breast cancer cell lines (i.e. MDA-MB 231, MCF-7 and T47D), cervical (HeLa) and leukemia (K-542).

Interestingly, most of the analyzed $\mathrm{CpG}$ sites showed intermediate methylation values, which was indicating again the presence of certain heterogeneity within the cell lines (Fig. 2A). Given that these samples lack of stromal derived alleles, these results revealed that the cancer cell lines are composed by different sub-clonal populations which are heterogeneous in epigenetic terms. It is important to note that, just like the 23 analyzed tumors, each cancer cell line presented a different and specific methylation profile.

Next, we calculated the HI values. In this opportunity, the number of methylated CpG sites in more than $10 \%$ of the samples ascended to 60 sites. We defined 12 random clusters of $5 \mathrm{CpG}$ sites (60 CpG sites) and calculated the $\mathrm{HI}$ of each cell line. Using ANOVA with post-hoc Tukey analysis we observed significant differences $(p<0.0001)$ in the $\mathrm{HI}$ among the cell lines (Fig. 2B). K-562 cells (leukemia) presented the highest heterogeneity with an $\mathrm{HI}=0.24$. The $\mathrm{HI}$ calculated for the other cell lines was, HeLa $=0.16, \mathrm{MCF} 7=$ $0.20, \mathrm{~T} 47 \mathrm{D}=0.15$ and MDA-MB231 $=0.16$. The average and SD HI value of the tumor cohort was $0.18 \pm 0.03$.

These results show that stable cancer cell lines present epigenetic heterogeneity, suggesting that the cell populations are composed by diverse cellular clones. It is worth mentioning that part of the heterogeneity observed may be due to aneuploidy, which is frequent in cancer cell lines.

\section{Cellular clones derived from MDA-MB 231 present diverse morphology and behavior traits}

Considering the epigenetic heterogeneity observed in different populations derived from cancer cell lines, we decided to focus on MDA-MB 231 since this cell line showed an intermediate heterogeneity index $(\mathrm{HI}=0.16)$. We asked whether this cell population could be separated in cellular clones that could explain the observed

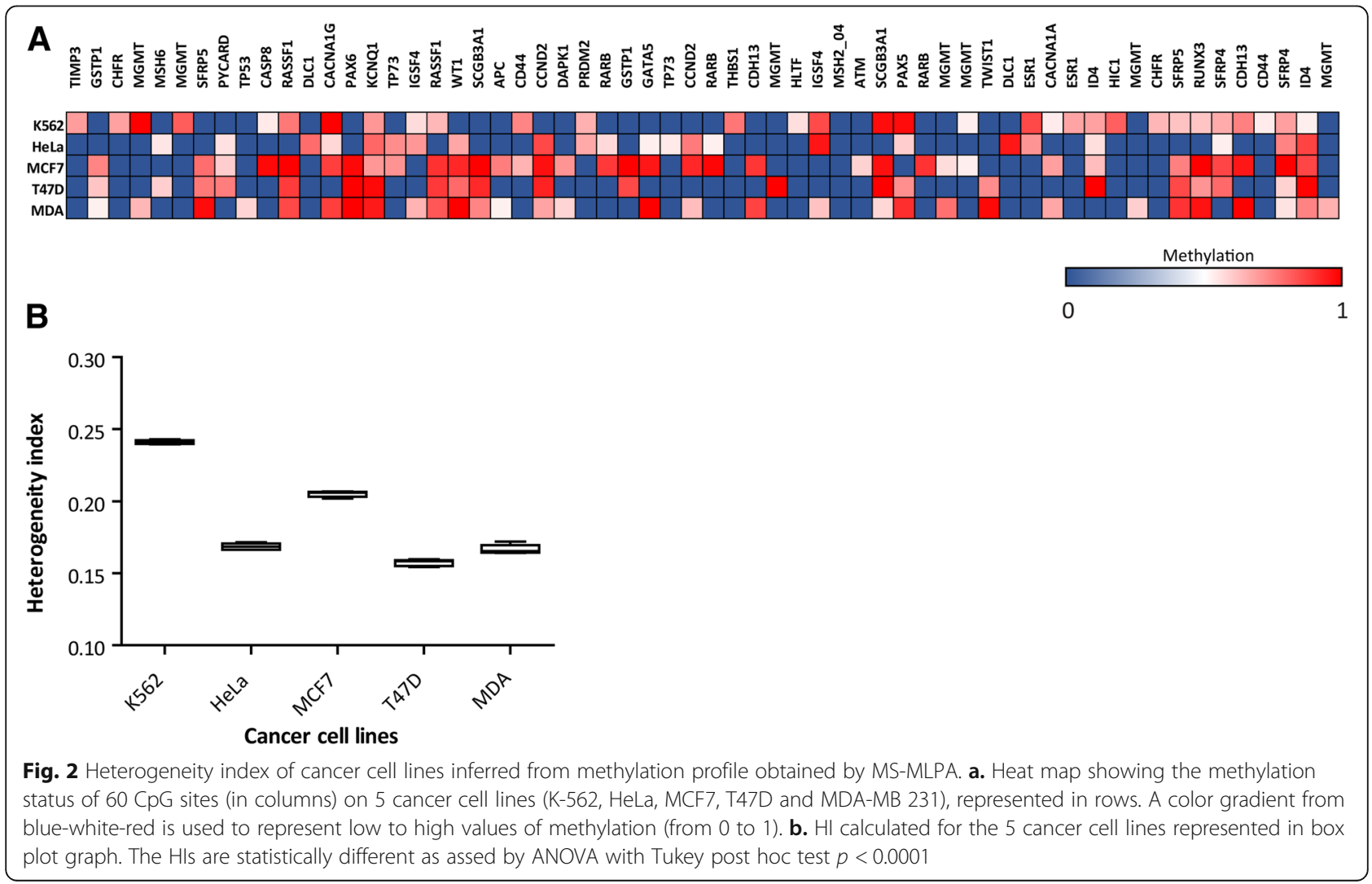


heterogeneity. For this, using a simple protocol of cell cloning by serial limiting dilution, an initial population of MDA-MB 231 (IP) was diluted to plate individual cells.

Five clones were selected with detectable differences in their proliferation rate (C7, H9, E5, G8 and E9 clones). After clone expansion, we observed that some of them presented different growth patterns. In addition, some clones displayed fibroblast-like phenotype (C7, E5 and E9) and others epithelial-like phenotype (H9 and G8) (Fig. 3A). Interestingly, each clone preserved phenotype and growth pattern along time ( 2 months, data not shown). We also studied morphological characteristics by flow cytometry. Significant differences were detected in internal cellular complexity (Side scatter) and no significant differences in cellular size (Forward scatter) by ANOVA test $(P=0.0016)$ and $(P=0.645)$ (Fig. $3 \mathrm{~B})$. These observations led us to ask whether the clones could present different behavior. When we studied the proliferation rate after $24 \mathrm{~h}$ and $48 \mathrm{~h}$ by MTT assay, we found significant differences among all the clones as compared to the initial population at $48 \mathrm{~h}$ (ANOVA $p<0.001$ ) (Fig. 3C). We also evaluated the apoptosis response to $30 \mathrm{~min}$ of UV irradiation using Annexin V/PI assessed by flow cytometry. As in the proliferation assay, we observed significant differences among the cellular clones $(p=0.01)$ (Fig. 3D). Finally, migration capacity of different clones was tested by wound-healing assay at 12 , 24, 36 and $48 \mathrm{~h}$. Again, some clones presented significant differences at 24 and $48 \mathrm{~h}$ of migration (ANOVA pos-hoc Tukey test $P<0.0021$ ) (Fig. 3E).

These results suggest that the initial population of MDA-MB 231 cells is epigenetically heterogeneous and is composed by different clones that show diverse morphology and behavior.

\section{MDA-MB 231 derived clones are heterogeneous in epigenetic terms}

The next question was if the clones were homogeneous in epigenetic terms. To address this question, we studied the methylation profile of the cellular clones by MS-MLPA. We observed different methylation patterns among clones which differed also as compared to initial population of MDA-MB 231 cells. Several CpG sites presented intermediate and different methylation values (between 0 and 1); which meant that these sub-populations derived from MDA-MB 231 were heterogeneous (Fig. 4A). We wondered which were the $\mathrm{CpG}$ sites that changed in the clones with respect to the IP. The rationality behind this was the idea that probably not all methylation sites would be able to modify the epigenetic landscape or generate equal advantages. We detected that each CpG site presented different dispersion between the distinct populations. Indeed, we observed that some sites (e.g. SCGB3A1, CCND2, ID4, GATA5, TP53, KCNQ1, CDH13, CACNA1G, SFRP5, PA

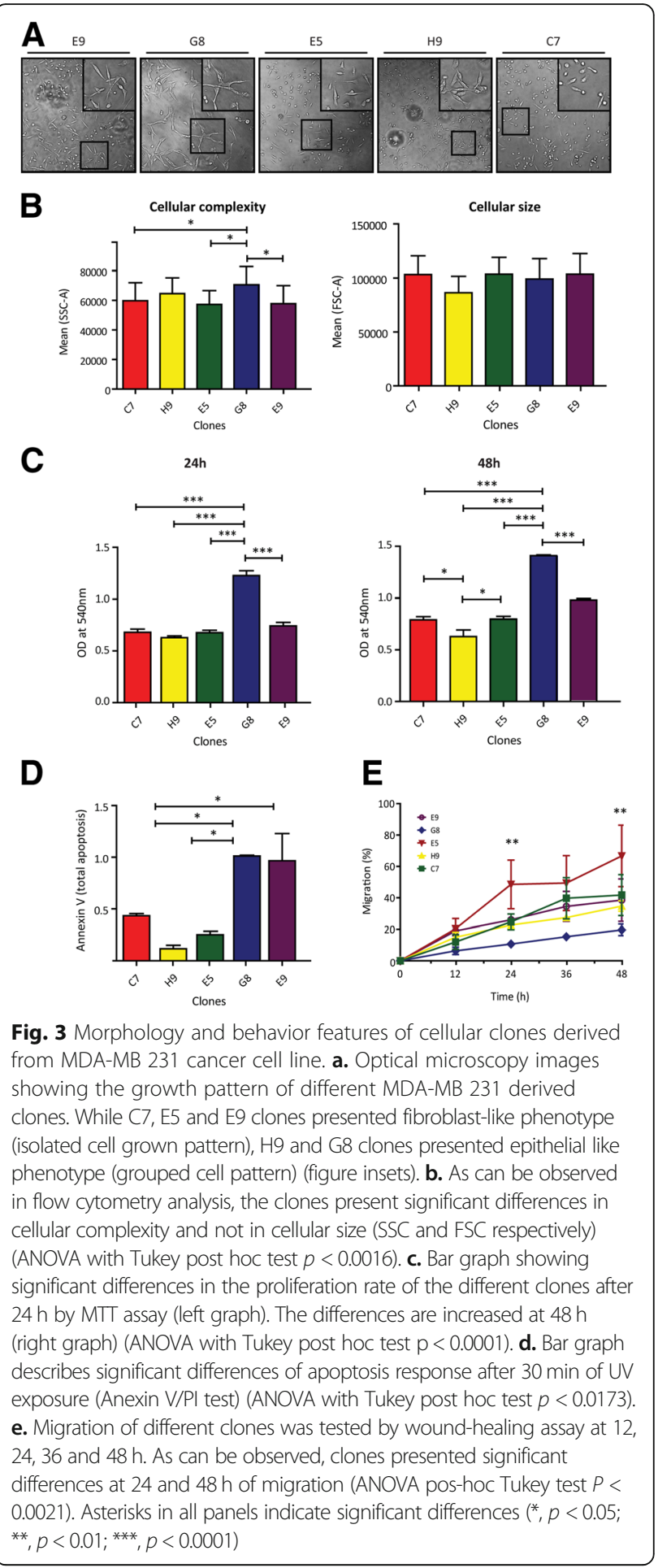

X6, WT1, CACNA1A, SCGB3A1, PAX5, TWIST1, IGSF4, SFRP5, RUNX3, RASSF1 and CDH13) were methylated in all the clones (in different proportions) and other sites were methylated in some clones (TIMP3, GSTP1, RASSF1, IGSF4, MGMT, CCND2, SFRP4, ESR1 and TP73) and unmethylated in others. Moreover, we detected methylation 
of some CpG sites that were not methylated in IP (TIMP3, MGMT, SFRP4, ESR1, and TP73). This observation suggests that the clones presented a different epigenetic profile respect to the IP; it is important to remark that not all the methylation sites underwent modifications to recreate heterogeneity in the one-cell derived clones.

We applied the HI calculation to measure the magnitude of the heterogeneity of the clones derived from
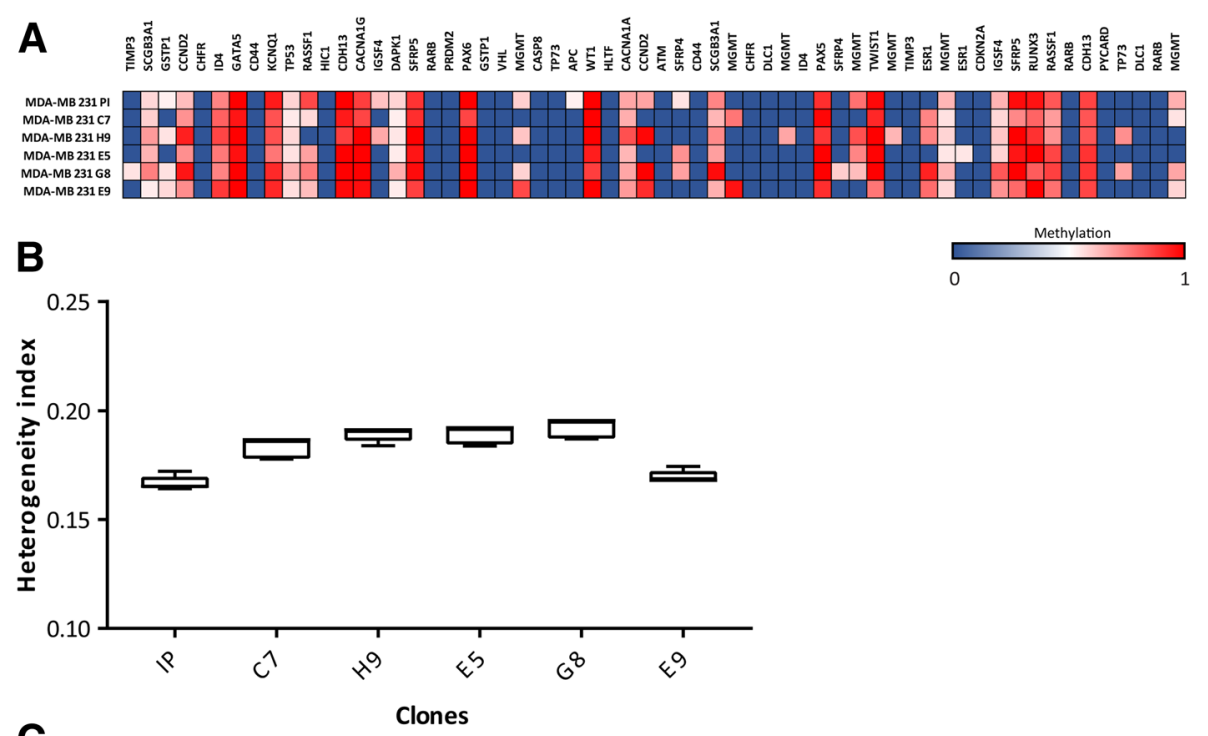

C

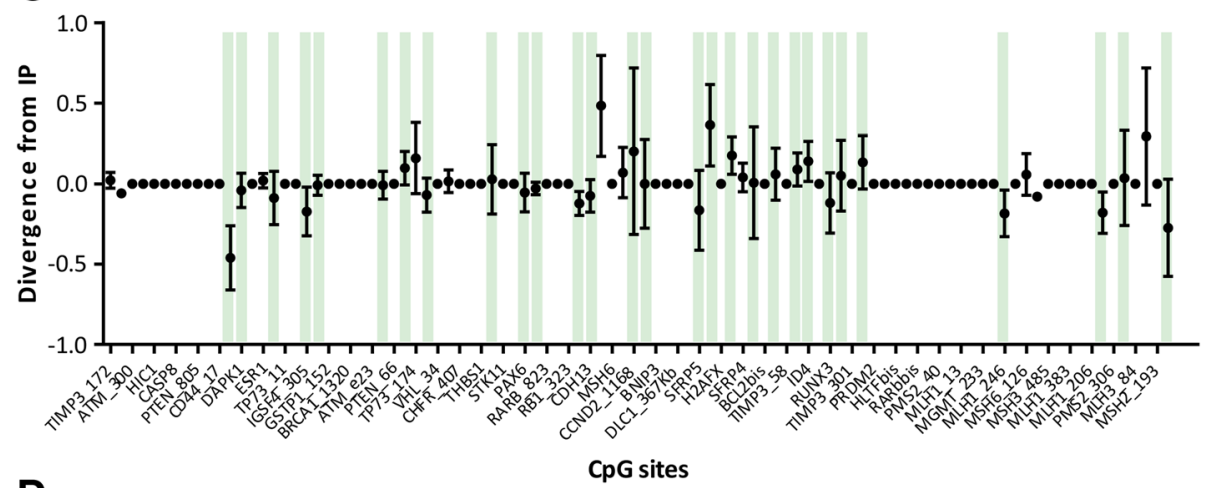

D

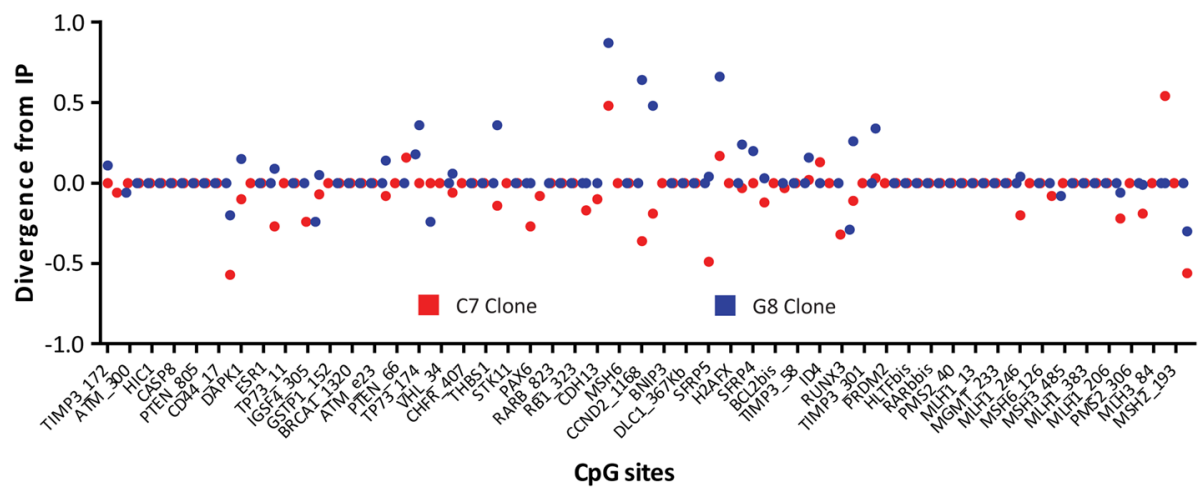

Fig. 4 Heterogeneity index of MDA-MB 231 clones inferred from methylation profile obtained by MS-MLPA. a. Heat map showing the methylation status of $60 \mathrm{CpG}$ sites (in columns) on MDA-MB 231 initial population and 5 clones (in rows). A color gradient from blue-white-red is used to represent low to high values of methylation (from 0 to 1). b. HI calculated for the MDA-MB 231 initial population (IP) and 5 clones represented in box plot graph. c. Scatter graph showing the methylation divergence from IP of $60 \mathrm{CpG}$ sites for all the clones. Divergence was defined as the difference of methylation value of the CpG sites between the clones and the initial population ( $\Delta=C l o n e-I P)$. Green bars show the CpGs methylated in the IP. d. Scatter graph showing the individual divergence of two clones. G8 clone (blue dots) diverged mostly increasing the methylation while C7 clone (red dots) diverged mostly decreasing the methylation of CpG sites 
MDA-MB 231 (Fig. 4B). Initially, we thought that clones would exhibit low heterogeneity. Unexpectedly, and despite the fact that clones had been originated from a single cell, the HI of these populations did not differ from the HI of the IP. Interestingly, they concentrated in a narrow range (0.16-0.19) around the HI of the IP.

From this analysis we could infer that, after 30-60 days (depending on the proliferation rate of each clones), sub-clonal cell populations generated from a single cell of a well-established breast cancer cell line would develop different methylation patterns. Interestingly, according to the $\mathrm{HI}$, the clones presented an epigenetic heterogeneity with a similar magnitude of the IP.

\section{Clones derived from MDA-MB 231 cells show epigenetic divergence without new selective pressure}

As we mentioned above, the clones were obtained from a single cell and were grown under controlled and non-competitive conditions for two months. As mentioned previously, we observed that the clones presented epigenetic heterogeneity despite no apparent new selective pressure was applied. So, we aimed to unravel if the heterogeneity observed in vitro is generated by epigenetic divergence of the clones.

To address this question, we defined epigenetic divergence as the difference between the clones and the IP of the 25 CpG sites methylation values $(\Delta=$ Clone - IP) (Fig. $4 C)$. Interestingly we observed a slight tendency to a positive divergence (hypermethylation) since $21 \mathrm{CpGs}$ increased the methylation proportion versus $18 \mathrm{CpGs}$ which diverged to unmethylation. However, if we analyze the divergence at individual level, we observed that each clone had its own divergence tendency. For example, the G8 clone (blue dots) diverged preferably by increasing the methylation while $\mathrm{C} 7$ clone (red blots) diverged rather by decreasing the methylation of CpG sites (Fig. 4D).

Another interesting observation was that most DNA methylation changes occurred in CpGs already methylated in the IP (Fig. 4C, green bars), suggesting that clones are the expansion of cell types that are representative of the prevalent population of the IP. An attractive exception was the methylation of ESR1, all clones presented methylation of this gene while it was unmethylated in the IP. All together, these evidences suggest that the methylation is not a random event.

Based on these observations, we conclude that the clone populations generated their own new heterogeneity mostly by altering the methylation state of $\mathrm{CpG}$ sites already methylated in the IP.

\section{HI correlates with clinic-pathological features of breast tumors}

We measured intratumor epigenetic heterogeneity in IDC from patients as well as in cellular clones. Since the clones $\mathrm{HI}$ were associated with different behavior, we aimed to see whether the HI of tumors could be associated to clinical-pathological features. We decided to test this hypothesis using a public resource such as TCGA which collects the data from several studies, with 250 tumors (Fig. 5A) and complete clinical-pathological information.

We selected $15 \mathrm{CpG}$ sites for the HI calculation in TCGA tumors (included in Table 2). Again, the selection was based on the most frequently methylated CpGs. As in the fresh tumor cohort, we observed a great dispersion in the HI obtained for the TCGA tumors (Fig. 5B). A significant positive correlation was found between HI and "Estrogen Receptor expression" $(\mathrm{r}=0.369 p<$ $0.0001)$ and "HER2 status" ( $\mathrm{r}=0.2264 p=0.0007)$.

Another remarkable observation was the positive correlation with "tumor stage" $(\mathrm{r}=0.1678 p=0.0121)$, "number of lymph nodes affected" ( $\mathrm{r}=0.2048 p=0.007)$ and "tumor size" $(\mathrm{r}=0.1713 p=0.0088)$.

These interesting results revealed an association between the epigenetic intratumor heterogeneity and relevant prognostic and predictive factors (like tumor size, number of affected axillary nodes and Estrogen receptor and HER2 positivity).

\section{Different cellular tumor populations share epigenetic heterogeneity index}

Until here, by using a mathematical model we inferred intratumor epigenetic heterogeneity from methylation data derived from fresh IDCs, cancer cell lines, cellular clones and TCGA tumors.

When comparing the information obtained from these diverse sources, we observed that the average $\mathrm{HI}$ was similar (ANOVA $p=0.53$ ), i.e.: fresh tumors $=0.1504$, cancer cell lines $=0.1888$, cellular clones $=0.1811$ and TCGA tumors $=0.1979$. Notice that we employed different number and different locations of CpG sites for the $\mathrm{HI}$ calculation on the distinct populations, making this convergence more surprising. In addition, surgical tumor margins presented a significantly lower HI $(0.0049)(p<$ $0.001)$. So, it is reasonable to propose that tumor cell populations share a similar HI which differs from healthy cellular populations.

Interestingly, we observed that the distinct molecular tumor subtypes (Basal like, Her2, Luminal A and Luminal B) presented different heterogeneity levels (ANOVA analysis $P<0.0021$ ) (Fig. 6B). By deepening in these observations, it is worth to notice that fresh tumors and TCGA tumors present a broad deviation from the mean. In line with this, when we ranked the HI values in "low" (from 0 to 0.17), "medium" (from 0.18-0.22) and "high" (above 0.22) we found that tumors were not distributed at random among these ranges. Most of the tumors (90\%) were distributed in the "low" or "high" rank, whereas only 10\% was included in the "medium" rank. In addition, a significant association was 


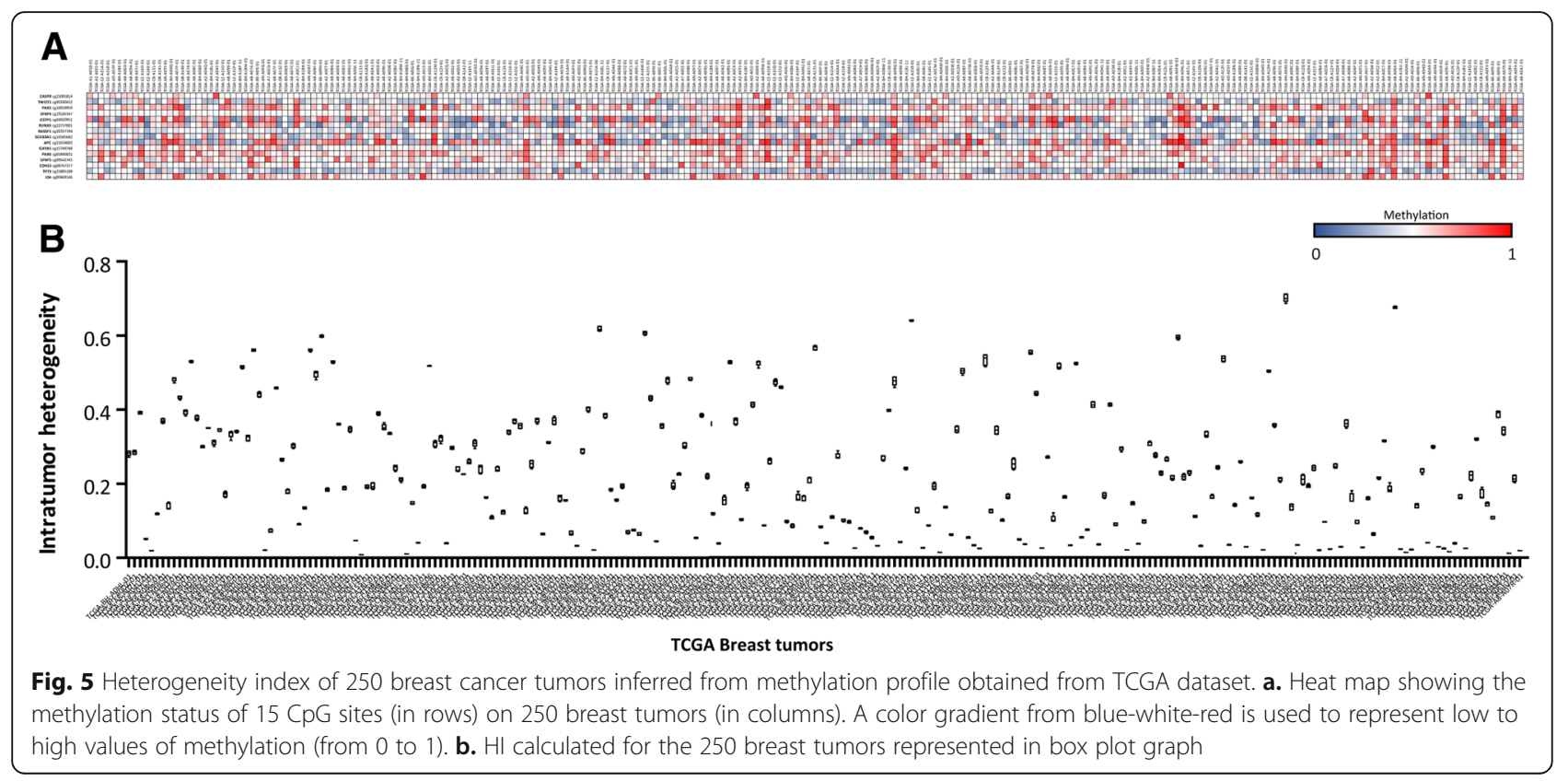

detected between the HI ranks and the tumor subtype PAM50 classification, i.e.: 38/ 42 (90\%) of basal like tumors presented "low" HI, while Luminal A and HER2 tumors were mostly equally distributed among "low" and "high" ranks; beside, more than the half (58\%) of Luminal B tumors were included in the "high" range of HI (Table 3).

We consider these observations very attractive since it suggests that, depending on the tumor type, the $\mathrm{HI}$ is deviated from the mean, increasing it in Luminal A, B, Her2 or decreasing it for basal like sub types.

\section{Discussion}

A tumor piece examined by a pathologist in a stained tissue or on a slide glass, is the final picture of an evolution process that started with a normal cell which acquired consecutive genetic and epigenetic alterations over time and as in all evolution processes, the outcome constitutes a heterogeneous population [27] [28] [3]. The resulting intratumor heterogeneity is one of the principal factors involved in resistance to standard oncological treatments and in tumor progression [4]. Several studies in solid tumors have addressed the intratumor heterogeneity as inferred from genetic mutations [29] [30], gene expression [31] [20] or protein modifications [32] [33]. Epigenomic alterations, which contrast with genomic alterations because of their dynamism and reversibility, evolve during a tumorigenic process in parallel to the acquisition of driving and passenger mutations
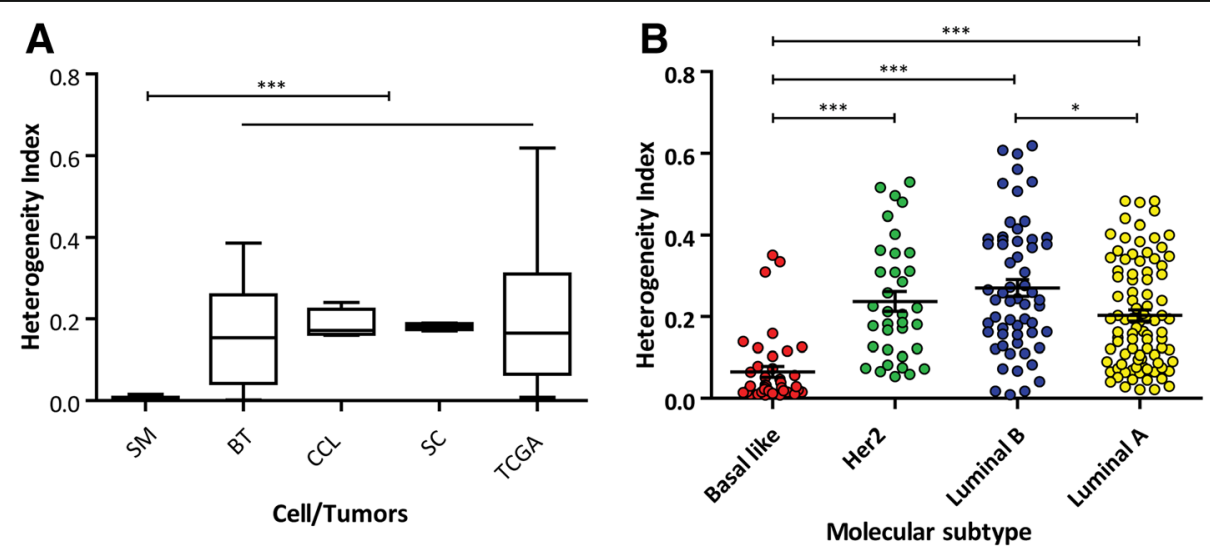

Fig. 6 Heterogeneity index average of cancer cell populations and normal cells obtained by MS-MLPA. a. Average HI for the different populations: breast tumor surgical margins (SM), breast tumors (BT), cancer cell lines (CCL), MDA-MB 231 clones (SC) and breast tumor TCGA dataset (TCGA). The HIs are statistically different as assed by ANOVA with Tukey post hoc test $p<0.0001$. b. Grouped column scatter graph showing the mean and SEM of different subtypes of the TCGA tumors (ANOVA with Tukey post hoc test $p<0.0001$ ) 
Table 3 Molecular subtypes of breast TCGA tumors

\begin{tabular}{|c|c|c|c|c|c|c|}
\hline & & \multicolumn{5}{|c|}{ Tumor subtype (PAM50) } \\
\hline & & Basal like & HER2 & Luminal A & Luminal B & Total \\
\hline \multirow[t]{4}{*}{ Grouped HI } & Low $(0-0.17)$ & 38 & 13 & 45 & 18 & 114 \\
\hline & Medium (0.18-0.22) & 0 & 7 & 11 & 7 & 25 \\
\hline & High (0.23-0.7) & 4 & 15 & 35 & 34 & 88 \\
\hline & & 42 & 35 & 91 & 59 & 227 \\
\hline
\end{tabular}

[34]. Therefore, they are relevant information for the study of spatial and temporal intratumor heterogeneity.

Different research works have described that cancer cells with specific mutations, present prominent sub-clonal diversification and that most of the genetic alterations are found in a fraction of the tumor [35] [36]. On the other hand, some authors have shown epigenetic heterogeneity by analyses of $\mathrm{CpG}$ methylation in different fractions of the same tumor in prostate and breast cancer [34] [37]. In this work we aimed to establish the intratumor heterogeneity magnitude as inferred from DNA methylation data.

We developed a heterogeneity index employing multiple markers (CpG sites) distributed in different regions of the human genome to quantify for the first time the epigenetic intratumor heterogeneity in breast cancer. For this, we established a mathematical model which conjugates the methylation information of multiple CpG sites located in promoter regions of TSG to generate a numerical index of heterogeneity of distinct cellular populations derived from different clinical and experimental models of breast cancer. It is important to stress that the CpG sites included in the index calculation are normally unmethylated in healthy cells, but frequently methylated in cancer cells. Therefore, alleles derived from the non-tumor cells only have a dilution effect in the index calculation. The HI can be also influenced by the copy number of the tumor cells because it pools together intra and inter cellular methylation heterogeneity. Considering this, tumors with multiple copy number alterations were excluded from this analysis. We also tested that $\mathrm{CpG}$ sites involved in the heterogeneity index calculation did not have significant copy number amplification in cancer cell lines nor in tumors. This is consistent with the fact that it is unlikely that TSG regions would be amplified in tumor cells [38] [39].

The starting point of this study was the observation of intermediate methylation values for multiple $\mathrm{CpG}$ sites in fresh IDC fractions derived from patients with breast cancer analyzed by MS-MLPA [16]. The same phenomenon can be observed in beta values of TCGA datasets, where DNA methylation profiles were measured experimentally using the Illumina Infinium HumanMethylation450 platform. Although the intermediate values of TSG methylation indicate ITH by themselves, the quantification of the heterogeneity allowed us to determine that not all tumors present the same level of heterogeneity. According to our hypothesis, using different sources of epigenetic information and different number of $\mathrm{CpG}$ sites, the HI obtained for each tumor was different. In fact, HI values presented high dispersion in both fresh and TCGA tumor cohorts. Therefore, if each tumor presents a specific heterogeneity value, this means that $\mathrm{HI}$ could be considerate as an individual tumor feature.

When we analyzed the $\mathrm{HI}$ in two different tumor cohorts (fresh tumors and TCGA tumors), we were surprised by the observation that they presented a similar HI mean (as well as in other tumor cell populations, discussed below), in contrast with the non-tumor population derived from de surgical margin which presented a lower HI mean. We previously mentioned that only $10 \%$ of the TCGA tumors presented HI values around the mean $(40 \%$ of tumors exhibit lower and $50 \%$ higher HI than the mean value). According to Nowell's model, these observations invite to propose an evolution mechanism involved in the generation of the ITH. Although more evidence is necessary to clearly explain this phenomenon, we propose to analyze the tumor cells as an ecological population where the local microenvironment shapes the epigenetic landscape leading the cell population to establish heterogeneity levels above or below a mean value. The same external conditions would create a selective pressure responsible for the establishment of different levels of HI. Higher HI values describe tumors with greater diversity among their cells, indicating probably the existence of a divergent selection pressure on the population. Divergent selection pressure is known to depress the adaptability of the individuals (or cells in this case) which represent the mean values, by favoring sub-groups with values distant from the mean. This kind of selective pressure disrupts the population maintaining high levels of divergence. On the contrary, lower HI values can be considered as indicative of populations tending to a homogenous value among the cells, where variability is not favored. This could be the case of a directional selective pressure, by which the population is shifted to a specific value and cells which carry this feature are positively selected. In this case, the tumor population is adapted through the acquisition of a specific feature, and therefore the $\mathrm{HI}$ is decreased among the cells. 
It has been described that although cancer cell line cultures do not reproduce cellular tumor architecture and intratumor heterogeneity, this experimental model could provide information on the clones functional features [40]. We detected ITH in different cancer cell lines and observed that the mean value of $\mathrm{HI}$ between these cell lines was similar to the mean HIs observed in both tumor cohorts. However, the dispersion of the HIs in cancer cell line populations was lower than the dispersion observed in tumors. This evidence is consistent with the fact that no apparent selective pressure is applied over cell culture populations, or that directional and divergence selective pressures are equated; in contrast to the tumors, where tumor cells are exposed to a strong environment constraint. Contrary to our speculations, clone populations derived from one of these cell lines, showed similar levels of heterogeneity than the initial population. This means that the generation of epigenetic heterogeneity in populations derived from a unique cell is possible after 1-2 month of proliferation. We determined divergence in epigenetic terms and different behavior of clones in the absence of specific selective pressure. Similar evidences were described in phenotypic and functional heterogeneity for different clones derived from single cell of MDA-MB 231 and MCF-7 cell lines at early stages of clonal development [41]. The HI mean value of the clone populations was similar to the other cancer populations (cell lines and tumors), however the HIs presented a lower dispersion even than cancer cell lines.

Taking into consideration the observation in cell lines and in breast tumors, we think that there is a mixed phenomenon, where the external factors affect the methylation landscape available to the cells and contribute to select and establish an epigenetic heterogeneity. Since in vitro experiments with cancer cell lines ( 5 cell lines and 5 clones), where no specific selective pressure was applied, and similar HIs were observed, we propose that in breast tumors the microenvironment acts over a basal heterogeneity characteristic of each tumor cell population.

It has been reported that tumors harboring high levels of genetic ITH were associated with more aggressive disease progression [42]. In this work we determined that early-stage tumors presented lower ITH levels in TCGA breast cancer tumors. However, the group of breast carcinomas with higher $\mathrm{HI}$ were enriched with luminal $\mathrm{A}$, luminal B and HER2 phenotypes which have a better prognosis than those with basal like phenotype [43]. In contrast, around $90 \%$ of basal like breast tumors was in the group with lower HI. Our hypothesis is that basal like tumors presented a lower variability, probably as a consequence of a directional selection process. It is important to mention that similar tendencies of association were observed between HI levels and tumor stage or ER and HER2 expression when we analyzed the fresh tumor cohort (data not shown).
Different measurement methods have been recently developed to express the observed intratumor heterogeneity as a numerical value [44] [45] [46]. The challenge is to obtain a useful clinical biomarker which could predict the risk of progression or response to treatment. The HI developed in this work contributes with this purpose and can be calculated using methylation profiles obtained with different methodological approaches. We consider that a deep exploration of this tumor feature using for example mathematical tools, is crucial both to unravel the mechanisms implicated in the spatial and temporal intratumor heterogeneity development and to improve the study of clinical tumor progression and treatment.

\section{Conclusions}

We developed an index to quantify for first time epigenetic heterogeneity in solid tumors inferred from tumor suppressor genes methylation patterns in different tumor cell populations (i.e fresh breast carcinomas, cancer cell lines and breast TCGA tumors). By applying the develop HI calculation, our analyses allow to conclude that all studied tumors or cultivated cells present heterogeneity, suggesting that epigenetic homogeneity is avoided during tumorigenesis. And even though we could establish that each tumor presents unique HI, our work shows also that some tumors share similar levels of HI in association with their subtype classification. We therefore conclude that tumor subtype's behavior could be described in terms of epigenetic heterogeneity, which could serve as a new contribution to understand the different prognosis of these groups.

\footnotetext{
Abbreviations

HI: Heterogeneity index; IDC: Invasive ductal carcinoma; TCGA: The Cancer Genome Atlas; TSG: Tumor suppressor genes
}

\section{Acknowledgements}

We thank Gabriel Flores for assistance in Java programming and for the development of web application for heterogeneity index calculation.

\section{Funding}

This work has been in part supported by a Grant from the Argentine National Institute of Cancer (INC) and Grant from Consejo Nacional de Investigaciones Cientificas y Técnicas (CONICET). These grants were necessary for the purchase of cell culture materials and reagents.

\section{Availability of data and materials}

The heterogeneity index calculation is available at: https://heterogeneidad. herokuapp.com/

\section{Authors' contributions}

EMC, MR and LSM conceived the study, and participated in its design and coordination. EMC and MTB collected samples and patient information, processed tumor tissue and did the MS-MLPA experiments. EMC designed and/or performed the in vitro experiment. EMC, MR and LSM performed the statistical analysis. EMC wrote the manuscript, prepared the figures and edited subsequent revisions. MR, LSM critically revised important intellectual contents in the manuscript and provided financial support. MTB helped to draft the manuscript. All authors read and approved the final manuscript. 


\section{Ethics approval and consent to participate}

Twenty three patients treated in the Gineco-Mamario Institute of Mendoza with breast cancer were enrolled after obtaining their written informed consent based on the scientific and ethical principles of the World Medical Association's Declaration of Helsinki. Ethical approval was obtained from the Ethics Committee of the Faculty of Medical Sciences, from the National University of Cuyo, Mendoza, Argentina (EXP-CUY 15856/2016).

\section{Consent for publication}

Not applicable.

\section{Competing interests}

The authors declare that they have no conflict of interest.

\section{Publisher's Note}

Springer Nature remains neutral with regard to jurisdictional claims in published maps and institutional affiliations.

\section{Author details}

${ }^{1}$ IHEM-CONICET, Av del libertador, 80 Mendoza, Argentina. ${ }^{2}$ Facultad de Ciencias Médicas, Av del Libertador 80, Universidad Nacional de Cuyo, Mendoza, Argentina. ${ }^{3}$ Facultad de Ciencias Exactas y Naturales, Padre Jorge Contreras 1300, Universidad Nacional de Cuyo, Mendoza, Argentina.

Received: 23 July 2018 Accepted: 28 March 2019

Published online: 05 April 2019

\section{References}

1. Ferlay J, Soerjomataram I, Ervik M, Dikshit R, Eser S, Mathers C, Rebelo M, Parkin DM, Forman D, Bray F. GLOBOCAN 2012 v1.1, Cancer incidence and mortality worldwide: IARC CancerBase no. 11. Lyon, France: International Agency for Research on Cancer. p. 2014.

2. DeSantis CE, Siegel RL, Sauer AG, Miller KD, Fedewa SA, Alcaraz Kl, et al. Cancer statistics for African Americans, 2016: Progress and opportunities in reducing racial disparities. CA Cancer J Clin. 2016.

3. McGranahan N, Swanton C. Clonal heterogeneity and tumor evolution: past, present, and the future. Cell. 2017.

4. Alizadeh AA, Aranda V, Bardelli A, Blanpain C, Bock C, Borowski C, et al. Toward understanding and exploiting tumor heterogeneity. Nat Med. 2015.

5. Nowell PC. The clonal evolution of tumor cell populations. Science [Internet] 1976;194(4260):23-28. Available from: http://www.ncbi.nlm.nih. gov/pubmed/959840

6. Swanton C. Intratumor heterogeneity: evolution through space and time. Cancer Res. 2012.

7. Szerlip NJ, Pedraza A, Chakravarty D, Azim M, McGuire J, Fang Y, et al. Intratumoral heterogeneity of receptor tyrosine kinases EGFR and PDGFRA amplification in glioblastoma defines subpopulations with distinct growth factor response. Proc Natl Acad Sci. 2012.

8. Liu X, George GC, Tsimberidou AM, Naing A, Wheler JJ, Kopetz S, et al. Retreatment with anti-EGFR based therapies in metastatic colorectal cancer: impact of intervening time interval and prior anti-EGFR response. BMC Cancer. 2015.

9. Gillies RJ, Flowers Cl, Drukteinis JS, Gatenby RA. A unifying theory of carcinogenesis, and why targeted therapy doesn't work. Eur J Radiol. 2012.

10. Müller HM, Widschwendter A, Fiegl H, Ivarsson L, Goebel G, Perkmann E, et al. DNA methylation in serum of breast Cancer patients: an independent prognostic marker. Cancer Res. 2003.

11. Baylin SB, Herman JG, Graff JR, Vertino PM, Issa JP. Alterations in DNA methylation: a fundamental aspect of neoplasia. Adv Cancer Res. 1998.

12. Jones PA. DNA methylation in development of bladder Cancer. Adv BI Res. 1999:419-23.

13. Lehmann U, Celikkaya G, Hasemeier B, Länger F, Kreipe H. Promoter hypermethylation of the death-associated protein kinase gene in breast cancer is associated with the invasive lobular subtype. Cancer Res. 2002.

14. Branham MT, Marzese DM, Laurito SR, Gago FE, Orozco Jl, Tello OM, et al. Methylation profile of triple-negative breast carcinomas. Oncogenesis. 2012.

15. Kober P, Boresowicz J, Rusetska N, Maksymowicz M, Goryca K, Kunicki J, et al. DNA methylation profiling in nonfunctioning pituitary adenomas. Mol Cell Endocrinol. 2018.
16. Campoy EM, Laurito SR, Branham MT, Urrutia G, Mathison A, Gago F, et al. Asymmetric cancer hallmarks in breast tumors on different sides of the body. PLoS One. 2016.

17. Kiss NB, Kogner P, Johnsen Jl, Martinsson T, Larsson C, Geli J. Quantitative global and gene-specific promoter methylation in relation to biological properties of neuroblastomas. BMC Med Genet. 2012.

18. Kim M, Costello J. DNA methylation: an epigenetic mark of cellular memory. Experimental and Molecular Medicine. 2017.

19. Mazor T, Pankov A, Song JS, Costello JF. Intratumoral heterogeneity of the epigenome. Cancer Cell. 2016.

20. Nik-Zainal S, Van Loo P, Wedge DC, Alexandrov LB, Greenman CD, Lau KW, et al. The life history of 21 breast cancers. Cell. 2012.

21. Shah SP, Roth A, Goya R, Oloumi A, Ha G, Zhao Y, et al. The clonal and mutational evolution spectrum of primary triple-negative breast cancers. Nature. 2012.

22. Gao R, Davis A, McDonald TO, Sei E, Shi X, Wang Y, et al. Punctuated copy number evolution and clonal stasis in triple-negative breast cancer. Nat Genet. 2016.

23. Lee J-Y, Yoon J-K, Kim B, Kim S, Kim MA, Lim H, et al. Tumor evolution and intratumor heterogeneity of an epithelial ovarian cancer investigated using next-generation sequencing. BMC Cancer. 2015.

24. Venkatesan S, Swanton C. Tumor evolutionary principles: how Intratumor heterogeneity influences Cancer treatment and outcome. Am Soc Clin Oncol Educ B. 2016

25. Almendro V, Cheng YK, Randles A, Itzkovitz S, Marusyk A, Ametller E, et al. Inference of tumor evolution during chemotherapy by computational modeling and in situ analysis of genetic and phenotypic cellular diversity. Cell Rep. 2014.

26. Marzese DM, Gago FE, Vargas-Roig LM, Roqué M. Simultaneous analysis of the methylation profile of 26 cancer related regions in invasive breast carcinomas by MS-MLPA and drMS-MLPA. Mol Cell Probes. 2010;24(5):271-80.

27. Marusyk A, Almendro V, Polyak K. Intra-tumour heterogeneity: a looking glass for cancer? Nat Rev Cancer [Internet] 2012;12(5):323-334. Available from: https://doi.org/10.1038/nrc3261\%5Cnhttp://www.ncbi.nlm.nih.gov/ pubmed/22513401

28. Yates LR, Gerstung M, Knappskog S, Desmedt C, Gundem G, Van Loo P, et al. Subclonal diversification of primary breast cancer revealed by multiregion sequencing. Nat Med. 2015.

29. Patel AP, Tirosh I, Trombetta JJ, Shalek AK, Gillespie SM, Wakimoto H, et al. Single-cell RNA-seq highlights intratumoral heterogeneity in primary glioblastoma. Science. 2014;80.

30. Janiszewska M, Liu L, Almendro V, Kuang Y, Paweletz C, Sakr RA, et al. In situ single-cell analysis identifies heterogeneity for PIK3CA mutation and HER2 amplification in HER2-positive breast cancer. Nat Genet. 2015.

31. Ennen M, Keime C, Kobi D, Mengus G, Lipsker D, Thibault-Carpentier C, et al Single-cell gene expression signatures reveal melanoma cell heterogeneity. Oncogene. 2014.

32. Irish JM, Hovland R, Krutzik PO, Perez OD, Bruserud $\varnothing$, Gjertsen BT, et al. Single cell profiling of potentiated phospho-protein networks in cancer cells. Cell. 2004.

33. Singh DK, Ku CJ, Wichaidit C, Steininger RJ, Wu LF, Altschuler SJ. Patterns of basal signaling heterogeneity can distinguish cellular populations with different drug sensitivities. Mol Syst Biol. 2010.

34. Brocks D, Assenov Y, Minner S, Bogatyrova O, Simon R, Koop C, et al. Intratumor DNA methylation heterogeneity reflects clonal evolution in aggressive prostate cancer. Cell Rep. 2014.

35. Torres L, Ribeiro FR, Pandis N, Andersen JA, Heim S, Teixeira MR. Intratumor genomic heterogeneity in breast cancer with clonal divergence between primary carcinomas and lymph node metastases. Breast Cancer Res Treat. 2007.

36. Park SY, Gönen M, Kim HJ, Michor F, Polyak K. Cellular and genetic diversity in the progression of in situ human breast carcinomas to an invasive phenotype. J Clin Invest. 2010.

37. Moelans CB, Verschuur-Maes AHJ, Van Diest PJ. Frequent promoter hypermethylation of BRCA2, CDH13, MSH6, PAX5, PAX6 and WT1 in ductal carcinoma in situ and invasive breast cancer. J Pathol. 2011;225(2):222-31.

38. Friedlander TW, Roy R, Tomlins SA, Ngo VT, Kobayashi Y, Azameera A, et al. Common structural and epigenetic changes in the genome of castrationresistant prostate cancer. Cancer Res. 2012.

39. Zhao M, Zhao Z. Concordance of copy number loss and down-regulation of tumor suppressor genes: a pan-cancer study. BMC Genomics. 2016.

40. Tostivint V, Racaud-Sultan C, Roumiguié M, Soulié M, Gamé X, Beauval J-B. Progress in prostate cancer study: 3D cell culture enables the ex vivo reproduction of tumor characteristics. Press Medicale. 2017. 
41. KHAN GN, KIM EJ, SHIN TS, LEE SH. Heterogeneous cell types in single-cellderived clones of MCF7 and MDA-MB-231 cells. Anticancer Res. 2017.

42. Harbst K, Lauss M, Cirenajwis H, Isaksson K, Rosengren F, Törngren T, et al. Multiregion whole-exome sequencing uncovers the genetic evolution and mutational heterogeneity of early-stage metastatic melanoma. Cancer Res. 2016.

43. Dvorkin-Gheva A, Hassell JA. Identification of a novel luminal molecular subtype of breast cancer. PLoS One. 2014

44. Graf JF, Zavodszky Ml. Characterizing the heterogeneity of tumor tissues from spatially resolved molecular measures. PLoS One. 2017.

45. Cheng Y, Dai JY, Paulson TG, Wang X, Li X, Reid BJ, et al. Quantification of multiple tumor clones using gene array and sequencing data. Ann Appl Stat. 2017.

46. Wang F, Dohogne Z, Jin Yang YL, Soibam B. Predictors of breast cancer cell types and their prognostic power in breast cancer patients. BMC genomics. 2018

Ready to submit your research? Choose BMC and benefit from:

- fast, convenient online submission

- thorough peer review by experienced researchers in your field

- rapid publication on acceptance

- support for research data, including large and complex data types

- gold Open Access which fosters wider collaboration and increased citations

- maximum visibility for your research: over $100 \mathrm{M}$ website views per year

At BMC, research is always in progress.

Learn more biomedcentral.com/submissions 